International Journal of Engineering \& Technology, $7(3.2)(2018) 128-130$
International Journal of Engineering \& Technology
SPC
Website: www.sciencepubco.com/index.php/IJET
Research paper

\title{
Improving of the Working Body's Screws Joining Elements Digging-Filling Piles
}

\author{
A.F. Gasimov ${ }^{1}$, R. R. Barkhalov ${ }^{2}$ \\ ${ }^{1}$ Azerbaijan University Architecture And Construction, Azerbaijan \\ ${ }^{2}$ Azerbaijan University Architecture And Construction, Azerbaijan \\ *Corresponding Author E-Mail: Ak675@Mail.Ru
}

\begin{abstract}
Extraction piles are widely used in the construction of industrial and civil buildings in poor, sloping slopes in the construction sector. Two methods are used in the placement of filling piles. First, the shingle-bell method is usually applied on the ground that does not explode. The latter is used primarily in avalanche and flowing grass, as well as in pressure and non-pressure aqueous soils. The parts of the body of the working body are coupled together with the help of couplings. These couplings work for both torsion and twisting. As a result of the gravity force of the large-diameter and deep wells connected to the reducer, the joining element of the couplings is bent. During disassembly, the connecting element is removed and can not be separated from the snap. This problem has once again been confirmed at meetings with producers participating in the BAUMA 2013 exhibition in Munich, Germany. In order to solve this problem it is planned to use the keysing pipe combination.
\end{abstract}

Keywords: pile, ground, shaft-wedge, screw, reducer, well, connecting element, keysing pipes.

\section{Introduction}

Bored piles have been widely used in building recently. They use two ways of placing bored piles. The first one called shinglebarbell is in use for non -collapsible soils. The latter non-stop screw method is mainly applied for collapsible and flowing soils as well as pressure and non-pressure saturated soils. The well with casing guarantees high quality of the foundation of the building, a long life of the foundation and the possibility of extracting the pile in emergency work. The technology using bored piles with a casing allows to perform the initial stage of construction on complex soils in a shorter time. This method is more expensive, but very effective, if you need to extract a part of the pile or filter from the hole. Foundation of the foundation and choice of casing pipes has its own characteristics.

LIEBHERR LRB 255 is a universal boring and piling machine for most types of piles.

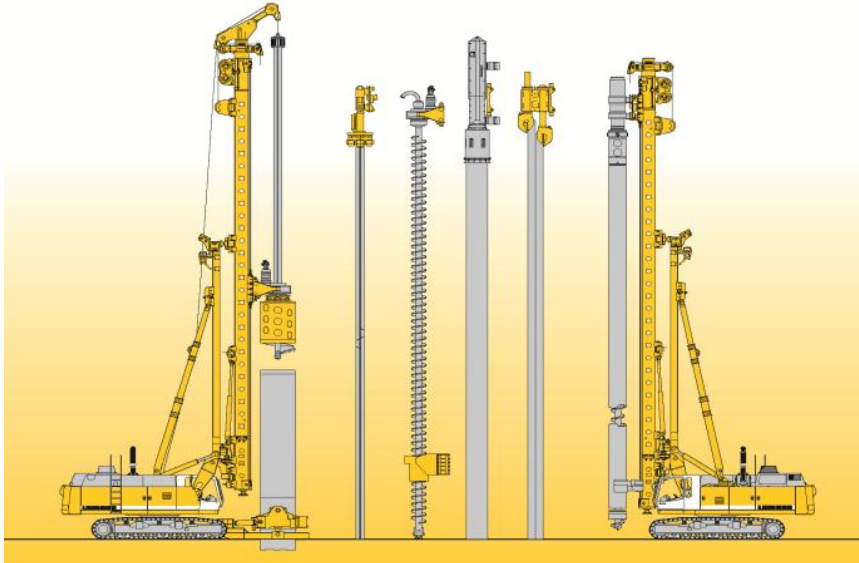

Fig. 1. Technology of the device of printed piles.
By means of replacing attachments, this drilling rig allows the use of up to seven technologies for the construction of submersible and pile-driven piles with a vibrator, hydraulic hammer, as well as for drilling with two drill heads, an endless auger screw or Rod Kelly. The Kelly Rod (Lead Rod) is used to transfer torque and pressure down from the drill rotator to the drilling tool [1].

Depending on the methods of creating cavities in the soil and methods of packing and sealing the material, the piles are divided into boron, pneumatic, rammed, frequency-tamped, sand and soilconcrete.

The main advantages of ramming piles:

- the possibility of making piles of any length;

-the absence of significant dynamic effects on the surrounding space during the construction of piles;

- applicability in constrained conditions;

- applicability when reinforcing existing foundations.

The length of the piles can reach $20 \ldots 30 \mathrm{~m}$ at a diameter of $50 \ldots$ $150 \mathrm{~cm}$. Piles made using special installations can have a diameter of up to $3.5 \mathrm{~m}$, a depth of up to $60 \mathrm{~m}$, a bearing capacity of up to 500 tonnes.

When drilling wells, there is practically no noise, shocks, vibrations, vibration - this fact allows using the CFA method for construction in tight urban conditions [2].

The complex of works on the construction of bored piles for the creation of pile foundations includes preparatory work, drilling of wells, filling with concrete mix of wells, installation of reinforcing cages, maintenance of the laid concrete and quality control of works. When the auger reaches a predetermined depth, concrete is fed through a concrete pump. The pressure created by the concrete pump when concrete passes through the hollow part of the screw extrudes a special plug, and concrete enters the well, while the auger rises, with or without rotation, freeing up space in the borehole. The filling density of the well is controlled by means of 
a special device displaying the shape of the pile in a graphical form on the display, or by means of a manometer to monitor the pressure of the concrete [3].

\section{Overview of Problem}

When using non-stop screw to place piles first a well is excavated by means of a screw. After the process of excavation is completed the well is filled with concrete through the pipe fixed in the screw by means of a pump. The concrete getting through the tip of the working body makes pressure which forces the screw to go upwards and at the same time making pressure on the walls of the well prevents the well from collapse and pressure waters from entering the well. This way the screw moves up and the concrete fills in its space. After the screw goes out of the well the latter is completely filled with concrete, in the further process a metal carcass is immersed in the concrete on the depth according to the design computation by means of a vibrator. During the process the compaction of the concrete takes place. The non-stop screw excavation is carried out by means of LIEBHERR LRB 255, Fundex 3500, ENTECO 300 and other equipment. The diameter of working bodies ranges from 600 to $1500 \mathrm{~mm}$, depth of excavation is from 12 to $40 \mathrm{~m}$. Depending on the diameter and depth the torque $\mathrm{T}$ forcing the screw ranges from $15-45 \mathrm{t} \cdot \mathrm{m}$. When the diameter and depth increase, the lifting force $\mathrm{Q}$ of the working body rises from 20 to 100 tons.

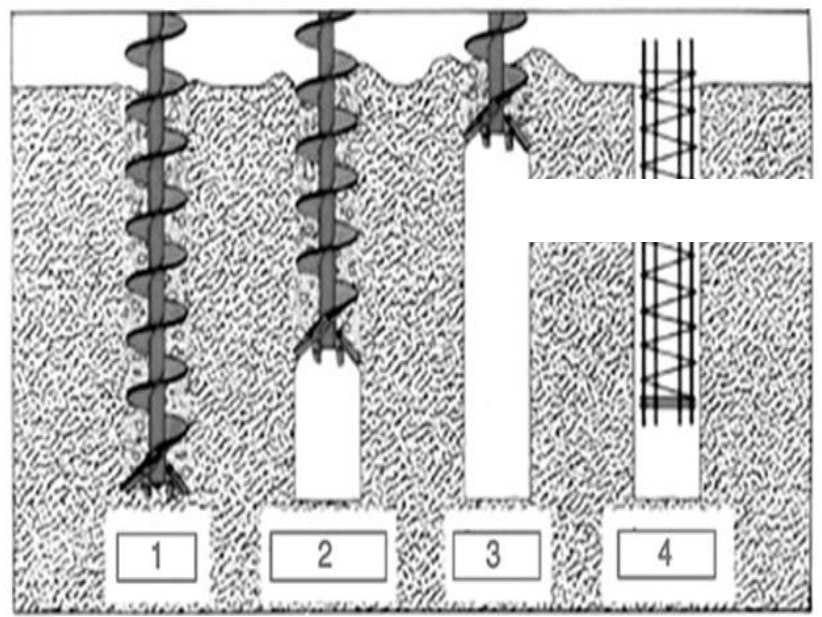

Fig.2. Constructive scheme of pored piles based on CFA technology

1-ground excavation by means of non- stop screw;

2-filling the well with concrete;

3 -completing concreting the well;

4-placement of vibrator and reinforcing cage.

The working body consists of several parts. The first one is a cutting part length of which ranges from 1,5 to $1,7 \mathrm{~m}$, the other parts are screws of different sizes 4,6 , and $8 \mathrm{~m}$. Joining these screws form a working body. They use couplings to join screws. The couplings work on both torsion and tension. When the diameter of screws or the depth where they work are considerable, the increase of gravity forcing their parts just fixed to the reducer ,in other words, the parts of coupling working on tension leads to their crumpe. As it is seen from the scheme ( figure 2 ) when screws are disassembled after the joining element is removed it is not possible to separate the screws. As it is seen in the figure it is impossible. In order to demount the screws used in the machine LIEBHERR LRB 255 working for Azertunnel Company in Azerbaijan they cut the coupling along the cross-section 1-1 shown in the scheme and then restore it.

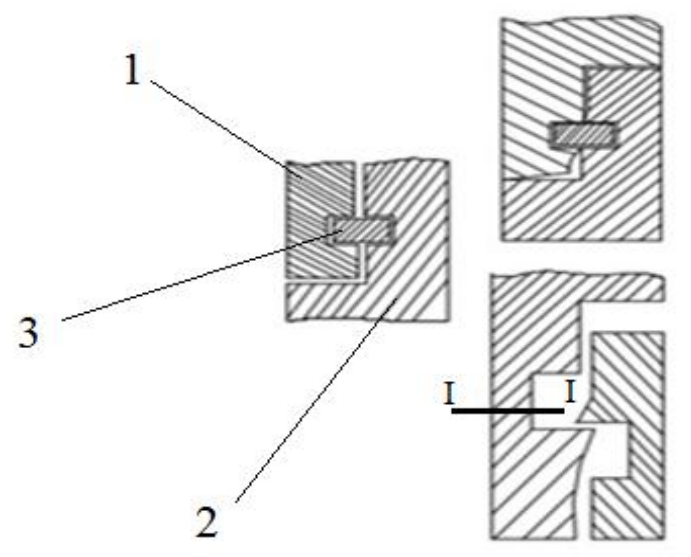

Fig.3. Deformation of coupling together with joining element: 1- first half coupling

2- second half coupling 3- joining element

Research shows that this problem exists for long screws of big diameters used in all countries. The problem has again been confirmed at meetings with producers participating in the BAUMA 2013 exhibition in Munich, Germany. In order to solve it they consider to use the type of the combination of casing pipes as the combination of screws. In order to increase the area of crumple they increase the number of rows as it is not possible to increase the number of combinations.

Torque forcing the screw

$$
T_{t . m}=45 \cdot t \cdot m
$$

Excavation resistance force

$$
Q=\frac{T_{a v}}{R-\frac{\delta}{2}}
$$

Here Q- resistance force, $t ; \mathrm{T}_{\mathrm{av}}$ - average torsion force, $\mathrm{t} \cdot \mathrm{m} ; \mathrm{R}$ radius of coupling, $\mathrm{m}$; - thickness of the wall of half coupling, $\mathrm{m}$; $\mathrm{P}$ - force acting on joining elements, $\mathrm{t}$;

$$
P=\frac{T_{a v}}{R-\left(\delta+\frac{\delta}{2}\right)}=\frac{T_{a v}}{R-1,5 \delta}
$$

Crumple stress is found as:

$$
\sigma=\frac{P}{z \cdot S}
$$

Here $S$ - the area of crumple, square metres; $\mathrm{z}$ - the number of combinations

$$
\begin{aligned}
& \frac{\delta}{b c}=\cos \beta, b c=\frac{\delta}{\cos \beta} \\
& h=b c \cdot \cos \frac{\alpha}{2}=\frac{\delta}{\cos \beta} \cdot \cos \frac{\alpha}{2} \\
& S=\frac{D_{1}+d}{2} \cdot h=\frac{D_{1}+d_{1}}{2} \cdot \frac{\delta}{\cos \beta} \cdot \cos \frac{\alpha}{2} \\
& S=\frac{D+d}{2} \cdot \frac{D-d}{2 \operatorname{tg} \frac{\alpha}{2}}=\frac{D^{2}-d^{2}}{4 \operatorname{tg} \frac{\alpha}{2}} \\
& \frac{l}{h}=\operatorname{tg} \frac{\alpha}{2}
\end{aligned}
$$




$$
\begin{aligned}
& h=\frac{l}{\operatorname{tg} \frac{\alpha}{2}}=\frac{D-d}{2 \operatorname{tg} \frac{\alpha}{2}} \\
& h=\frac{\operatorname{tg} \frac{\alpha}{2}}{\frac{D-d}{2}}=\frac{2 \operatorname{tg} \frac{a}{2}}{D-d} \\
& S=\frac{D+d}{2} \cdot \frac{2 \operatorname{tg} \frac{a}{2}}{D_{P}-d} \\
& \sigma=\frac{P}{z \cdot S}=\frac{P}{(D+d) \cdot 2 \operatorname{tg} \frac{\alpha}{2} \cdot z} \\
& =\frac{P \cdot 2(D-d)}{(D-d) 2 \operatorname{tg} \frac{\alpha}{2} \cdot z}
\end{aligned}
$$

On the other hand the following condition should be met:
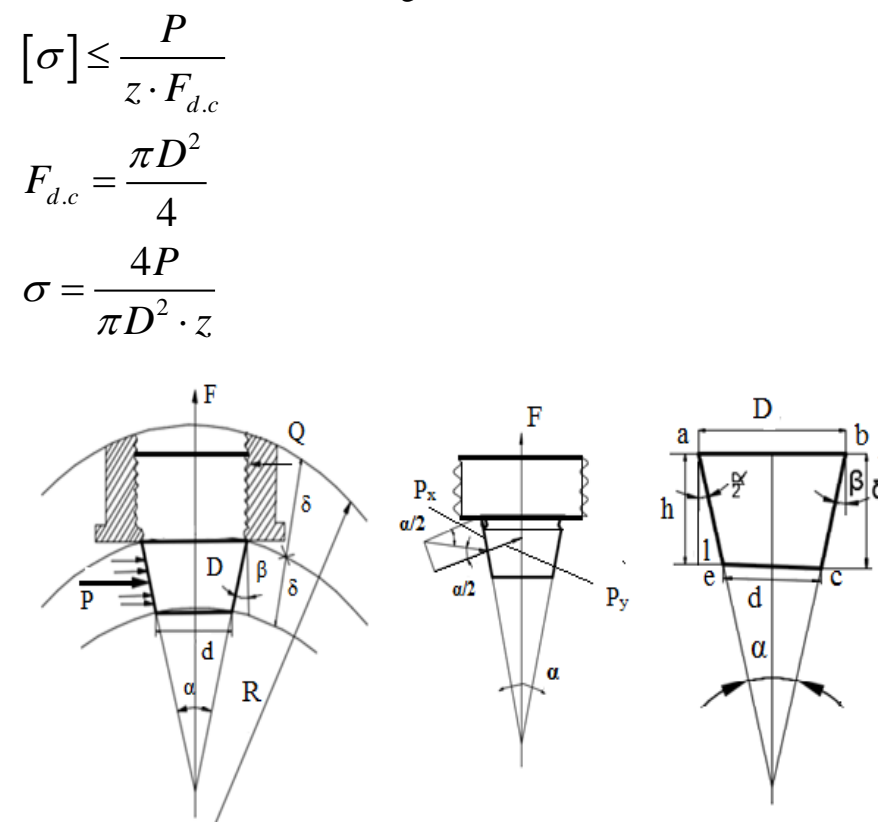

Fig. 4. Design scheme of joining element

During work from the other side radial force $\mathrm{F}$ acts on the combination as well as the screw-thread. Taking that into consideration force $\mathrm{F}$ can be found

$$
\begin{aligned}
& \frac{P_{x}}{p}=\sin \frac{\alpha}{2} \\
& P_{x}=P \cdot \sin \frac{\alpha}{2} \\
& P_{y}=F=P_{x} \cdot \cos \frac{\alpha}{2} \\
& \frac{F}{P_{x}}=\cos \frac{\alpha}{2}
\end{aligned}
$$

$$
F=P_{x} \cdot \cos \frac{\alpha}{2}=P \cdot \sin \frac{\alpha}{2} \cdot \cos \frac{\alpha}{2}
$$

Besides the piles mentioned above one of the piles intruded into each other is metal netty, the other one is non-metal netty. In the first turn a non-metal pile is excavated. Then they skip the site of a pile. After that the second non-netty pile is excavated. One or two days later the space between both the piles is excavated in such a way that a new excavated pile well is intruded into either pile at $150 \mathrm{~mm}$.

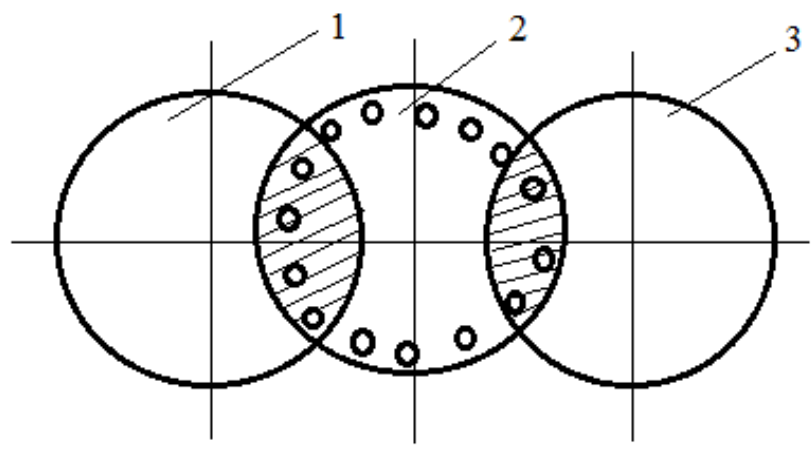

Fig.5. Scheme of placeacement of piles 1,3 - non- metal netty piles, 2 - a metal netty pile

When cutting part transits from ground to concrete dynamic forces act. That impacts on the joining element and at the same time changes the straight direction of screw motion. They recommend to use not two but three rows of joining elements of screws working under these conditions.

Conclusion. The usage of such kind of combination makes easy demounting the screws of a working body. At the same time the screws of working body have limited displacements relative to each other in both along the axis and radial directions. So the screws joined together remain intact, that prevents the swinging working body from its touching the walls of the excavated well. As a result, the diameter of an excavated well does not change which saves extra concrete.

\section{References}

[1] Badin G.M, Sychev S.A, Modern technologies of building and reconstruction of buildings, Design, Publishing House BHV-Petersburg, 2013.$288 \mathrm{p}$

[2] Sokolov G.K. Technology and organization of construction: a textbook for stud. Wednesdays, prof. Education / - 5 th ed., Rev. - Moscow: Publishing Center "Academy", 2008. - 528 p

[3] Verstov, V.V. Technology of piling foundations: Textbook. allowance / SPbGASU - St. Petersburg, 2010. - 180 p.

[4] Korobko B. (2016), Investigation of energy consumption in the course of plastering machine's work, Eastern-European Journal of Enterprise Technologies, 4/8 (82), 4 - 11. DOI: 10.15587/1729-4061.2016.73336.

[5] Fleming K. Piling Engineering / K. Fleming, A. Weltman, M. Randolph, K. Elson. - London and New York: Taylor and Francis. - 2008. - 398 p.

[6] Chau K. Numerical Methods / K. Chau // Proc. of the 18th Intern. Conf. on Soil Mechanics and Geotechnical Engineering. - Paris. - 2013. - P $647-654$.

[7] Zotsenko M. L. BurovI GruntotsementnI palI, yakI vigotovlyayutsya za burozmIshuvalnim metodom / M. L. Zotsenko, Yu. L. Vinnikov, V. M. Zotsenko. - H. : «Madrid», 2016. - 94 s.

[8] Zotsenco, M. L. (2011). Soil-cement basement and foundation. Building constructions, №75, v. 1, 447 - 457

[9] Petrash, A. V. (2013). Insurance of effective service of underground structures of engineering installations which made of soil-cement. Collection of scientific papers. Series: sector machinery construction, building, №4 (34), v. $2,178-183$.

[10] Zotsenco, M. L., Korshunov, M. O., Petrash, R. V., Petrash, S. S. (2007) Economy of energy resource by using soil-cement piles as foundation of buildings and constructions. Economy and region: scientific reporter, №2 (13), $51-54$. 